\title{
. \\ Recycling Cigarette Filters as Plant Growing Substrate in Soilless System
}

\author{
Lorenzo Mariotti ${ }^{1,2}\left(\mathbb{0}\right.$, Thais Huarancca Reyes ${ }^{1, *} \mathbb{C}$, Maurizio Curadi ${ }^{2}$ and Lorenzo Guglielminetti ${ }^{1,2}$ \\ 1 Centro di Ricerche Agro-Ambientali “E. Avanzi”, University of Pisa, Via Vecchia di Marina 6, San Piero a \\ Grado, 56122 Pisa, Italy; lorenzo.mariotti@unipi.it (L.M.); lorenzo.guglielminetti@unipi.it (L.G.) \\ 2 Department of Agriculture, Food and Environment, University of Pisa, Via Mariscoglio 34, 56124 Pisa, Italy; \\ maurizio.curadi@unipi.it \\ * Correspondence: thais.huarancca@agr.unipi.it
}

check for updates

Citation: Mariotti, L.; Huarancca Reyes, T.; Curadi, M.; Guglielminetti, L. Recycling Cigarette Filters as Plant Growing Substrate in Soilless System. Horticulturae 2022, 8, 135. https:// doi.org/10.3390/horticulturae8020135 Academic Editor: Francesco Di Gioia

Received: 13 January 2022 Accepted: 31 January 2022 Published: 3 February 2022

Publisher's Note: MDPI stays neutral with regard to jurisdictional claims in published maps and institutional affiliations.

Copyright: (C) 2022 by the authors. Licensee MDPI, Basel, Switzerland. This article is an open access article distributed under the terms and conditions of the Creative Commons Attribution (CC BY) license (https:// creativecommons.org/licenses/by/ $4.0 /)$.

\begin{abstract}
Two massive wastes are cigarette butts (CB) and stone wool (SW), both representing a threat to the environment. Although the cellulose acetate filters (CAF) in CB are long-term degradable, SW soilless substrates are not. Here, a soilless substrate for growing ornamental plants was manufactured with CAF and compared to commercial SW substrate. CB treatment consisted of a washing in boiling water with a dramatic reduction of pollutants in CAF. Then, cleaned filters were separated, dried, carded to fibers, and subsequently compacted into plugs. The trace pollutants in recycled CAF substrate did not negatively affect the germination of Spartium junceum L. and Lavandula angustifolia Miller seeds as well as the root development of Salvia officinalis L. and Salvia rosmarinus Schleid. stem cuttings. Plants grown in recycled CAF showed a differential species-dependent change of pigments in comparison with those in SW, without compromising their photosynthesis performance. Overall, the results demonstrated that these plants can be well established and grow in recycled CAF, as comparable to SW substrate. This study highlights a novel and promising solution in CAF recycling by turning this litter into an efficient soilless substrate for growing ornamental plants, thus limiting the use of SW and indirectly decreasing its industrial waste flow.
\end{abstract}

Keywords: anthropogenic litter; recycling solution; soilless substrate; ornamental plants; physiological traits

\section{Introduction}

Over recent decades, artificial substrates other than soil in which plants are grown have been increasingly used in many greenhouse systems [1]. For instance, one of the major greenhouse substrates in Europe is stone wool (SW) made by Grodan ${ }^{\circledR}$, which is mainly in the form of slabs, blocks, or plugs of bonded fibers [2]. Although SW, also known as rockwool, has been initially produced for thermal and acoustic insulation in the construction industry, its attractive application as a substrate started in 1969 [3].

The production process of SW requires a high amount of energy, water, and raw material consumption. Moreover, this process generates great environmental impacts due to the release of dust and toxic gaseous compounds [4]. Despite manufacturing disadvantages, SW substrates are preferably used in soilless systems because they are inert, sterile, easy to manage, and consistent in performance [3]. However, SW is usually discarded after one to sometimes three crop cycles, producing a high volume of waste [1] The global volume of waste when considering all SW applications is expected to rise to 2.82 million tons per year by 2030 [5]. Because SW is not biodegradable and cannot always be recycled, the massive waste is a major environmental concern.

Nowadays, the development of a new sustainable process and materials is of extreme importance in the greenhouse industry in order to significantly impact on the social level and reduce environmental repercussion. This, of course, includes waste management during the production cycle. In this context, eco-friendly substitutes for SW substrate 
have been tested in soilless culture systems for some vegetables, such as the use of some cellulosic materials [6]. Regarding cellulosic materials, cigarette filters represent a zero cost and are a widely available reservoir of cellulose acetate, which is practically boundless if considering that cigarette butts $(\mathrm{CB})$ are improperly littered in the environment [7].

$\mathrm{CB}$ contain toxic compounds accumulated during smoking including arsenic, benzene, hydrogen cyanide, polycyclic aromatic hydrocarbons, pyridine, and heavy metals [8-12]. Moreover, CB disposal systems (i.e., landfilling and incineration) are costly and release hazardous compounds to the environment $[13,14]$. Recently, CB, as starting raw materials, have been used essentially for the production of mesoporous carbon, cellulose pulp, and asphalts [14,15]. However, no attempts have been reported until now on their use to produce substrates for soilless culture systems, considering that cellulose acetate filters (CAF) in CB are a long-term degradable material [16].

Following our interest in circular economy and sustainable development, in the present study, we propose to recycle CAF as a soilless substrate for growing ornamental plants commonly used in the Mediterranean green urban spaces. In order to ensure low contamination of CAF, the cleaning process of CB was analytically evaluated. Subsequently, CAF was recycled as a growing substrate and evaluated as a replacement for commercial SW in a soilless system. In this line, the establishment of roots, progressive growth, and development of four ornamental plants (Spartium junceum L., Lavandula angustifolia Miller, Salvia rosmarinus Schleid., and Salvia officinalis L.) were assessed, comparing seeding or cutting in recycled CAF substrates with those in SW. We hypothesized that ornamental species can grow and tolerate the possible remaining compounds in recycled CAF substrate, as these species are commonly used to recover contaminated areas [17], contributing to the resilience of ecosystems and human wellbeing [18].

\section{Materials and Methods}

\subsection{Collection and Treatment of $C B$}

$\mathrm{CB}$ were collected from public collectors in coffee bars located in the surroundings of the municipality of Capannori (Lucca, Italy). The cleaning process was performed by an exhaust boiling of CB (100 g) in distilled water $(1 \mathrm{~L})$ for $10 \mathrm{~min}$. The wastewater was collected for a further chemical characterization, whereas the cigarette filters were manually separated and dried up at room temperature. Finally, CAF were manually carded with a metal comb in order to obtain fibers, subsequently compacted by pressure $\left(1 \mathrm{Kg} \mathrm{cm}^{-2}\right)$ into plugs of $2.5 \mathrm{~cm}$ height $\times 2 \mathrm{~cm}$ diameter $(1 \mathrm{~g}$ fibers each plug) contained in multiwell blocks, whereby an identical appearance between CAF and Grodan ${ }^{\circledR} \mathrm{SW}$ substrate plugs was achieved.

\subsection{Analytical Determinations}

Aliquots of wastewater were dried under vacuum and re-eluted with acetone and heptane $50 \%(v / v)$. Determination of the analytes in the wastewater was performed by highresolution GC-MS analysis, using a Saturn 2200 quadrupole ion trap mass spectrometer coupled to a CP-3800 gas chromatograph (Varian Analytical Instruments, Walnut Creek, CA, USA) equipped with a MEGA-SE54 HT capillary column (10 m; 0.15 mm i.d., $0.10 \mu \mathrm{m}$ film thickness, MEGA s.n.c., Milan, Italy). The carrier gas was helium, which was dried and air free, with a linear speed of $60 \mathrm{~cm} / \mathrm{s}$. The oven temperature was maintained at $60{ }^{\circ} \mathrm{C}$ for $2 \mathrm{~min}$ and increased to $350{ }^{\circ} \mathrm{C}$ at a rate of $10{ }^{\circ} \mathrm{C} / \mathrm{min}$. Full-scan mass spectra was obtained in $\mathrm{EI}^{+}$mode with an emission current of $10 \mu \mathrm{A}$ and an axial modulation of $4 \mathrm{~V}$. Data acquisition was from 10 to $550 \mathrm{Da}$ at a speed of $1.4 \mathrm{scan} / \mathrm{s}$. Chromatogram peaks were identified by comparing their mass spectra with the NIST library database. Quantification was performed using the relative abundance of chromatogram peaks.

\subsection{Evaluation of Substrates as Plant Growing Media in Soilless System}

Seeds of Spartium junceum L. (Spanish broom) and Lavandula angustifolia Miller (lavender) were germinated in plugs of recycled CAF or commercial SW (Grodan, Roermond, 
the Netherlands), where the latter was used as control. Similarly, Salvia rosmarinus Schleid. (rosemary) and Salvia officinalis L. (sage) were propagated in the aforementioned substrate plugs by stem cutting. The growth chamber was set at a $12 \mathrm{~h}$ light/12 h dark photoperiod, with temperature $22 \pm 1{ }^{\circ} \mathrm{C}, 75 \%$ relative humidity, and $100 \mu \mathrm{mol} \mathrm{m}{ }^{-2} \mathrm{~s}^{-1}$ photosynthetically active radiation (PAR). Irrigation was applied as needed to the top of the substrates in order to prevent wilting, and nutrient solution was supplied once a week.

The germination percentage ( 3 replicates of 100 seeds per replicate) and capacity to form new roots ( 3 replicates of 100 cuttings per replicate) were monitored in a time course within 8 and 12 weeks, respectively. The root formation capacity was referred to as the number of cuttings with new root initials, which was counted by using magnifying binoculars and expressed in percentage. In order to assess the health status of plants, chlorophyll $a$ fluorescence and photosynthetic pigments were determined at the end of the experimental period in three biological replicates. The maximum photosystem II (PSII) photochemical efficiency $\left(F_{v} / F_{m}\right)$ in dark adapted leaves, and the photochemical yield of PSII in the light ( $\left.\Phi_{\text {PSII }}\right)$ under actinic illumination of $100 \mu \mathrm{mol} \mathrm{m} \mathrm{m}^{-2} \mathrm{~s}^{-1}$ PAR were measured by using a miniaturized pulse amplitude-modulated fluorometer (MiniPAM; Heinz Walz GmbH, Effeltrich, Germany) as reported [19]. Photosynthetic pigments, including chlorophyll $a(\mathrm{Chl} a)$, chlorophyll $b(\mathrm{Chl} b)$, and total carotenoids (Car) were extracted and analyzed as previously reported [20].

\subsection{Statistical Analysis}

Values presented are means of three replicates. The significant differences among means were estimated at the level of $p<0.05$ by Tukey's test, in which the statistical analysis was performed by STATISTICA for Windows, version 13.4.0 (Start-Soft, Inc., Tulsa, OK, USA) using a one-way analysis of variance.

\section{Results and Discussion}

\subsection{Chemical Characterization of CB Treatment}

In order to ensure a low content of remaining toxic compounds in the filters from treated $\mathrm{CB}$, filters obtained after the first cleaning process were subjected to a second washing in boiling water for $10 \mathrm{~min}$, resulting in two wastewater samples, from the first and second boiling. The chemical characterization of the first boiling samples showed that our treatment removed several pollutants (Table 1). Moreover, results from the second boiling samples suggested that filters were well cleaned, as the relative abundance of chemicals dramatically decreased, especially of the most abundant molecules, such as pyridine, 3-(1-methyl-2-pyrrolidinyl); silane, trimethyl[(1-propylpentyl)oxy]; and pyridine, 3-(1-methyl-1H-pyrrol-2-yl) (Table 1). Therefore, since a significant reduction of pollutants (approximately 90\%) was found comparing first and second boiling samples, it was decided that a one-time cleaning process was enough to recycle filters from CB. It is worth mentioning that the presented list of chemical compounds can be changed depending on the solvent used during treatment and the identification method [21]. Further additional experiments including the $\mathrm{CB}$ wastewater treatment by microalgal-based remediation techniques, in line with circular economy principles, are currently in progress with promising results. 
Table 1. Chemical characterization of cigarette butts treatment. Relative abundance (kcounts) of different compounds contained in the wastewater from first and second boiling of cigarette butts. Total represents the sum of the relative abundance of compounds in each boiling sample, whereas the residual (\%) was obtained by comparing the total abundance between first and second boiling samples. Data are means of 3 different replicates. Asterisks represent significant differences $(p<0.05)$ between first and second boiling samples. Instrument detection limit $<400$ counts. ND, not detectable.

\begin{tabular}{|c|c|c|c|}
\hline \multirow{2}{*}{$\begin{array}{l}\text { Retention Time } \\
\text { (min) }\end{array}$} & \multirow[t]{2}{*}{ Compound } & \multicolumn{2}{|c|}{$\begin{array}{l}\text { Relative Abundance } \\
\text { (Kcounts) }\end{array}$} \\
\hline & & 1st Boil & 2nd Boil \\
\hline 5.666 & benzonitrile & 25 & 22.5 \\
\hline 5.737 & silane, methoxytripropyl & 35 & 20 * \\
\hline 5.873 & 1,2,3-propanetriol, diacetate & 45 & ND \\
\hline 6.630 & pyridine, 3-(1-methyl-2-pyrrolidinyl) & 800 & 30 * \\
\hline 7.097 & silane, trimethyl[(1-propylpentyl)oxy] & 400 & $75 *$ \\
\hline 8.577 & pyridine, 3-(1-methyl-1H-pyrrol-2-yl) & 80 & $6.5 *$ \\
\hline 9.116 & benzoic acid, 4-ethoxy-, ethyl ester & 6 & $3.5 *$ \\
\hline 9.646 & dodecane, 1 -chloro & 7 & $4 *$ \\
\hline 9.698 & octadecanol & 3 & 3 \\
\hline 10.407 & $\begin{array}{c}\text { 2-cyclohexen-1-one, } 4(3-\text { hydroxy-1-butenyl)-3-5-5- } \\
\text { trimethyl }\end{array}$ & 6.5 & 6 \\
\hline 11.494 & eicosanol & 6 & $4 *$ \\
\hline 12.043 & 1H-indole-3-acetonitrile & 7 & ND \\
\hline 12.737 & 1,2-benzenedicarboxylic acid, bis(2-methylpropyl) ester & 9 & $2.75 *$ \\
\hline 13.370 & pentadecanoic acid, 14-methyl-, methyl ester & 20 & ND \\
\hline 13.660 & dibutyl phthalate & 25 & 10 * \\
\hline 13.986 & 3-indoleacetonitrile, 7-methoxy & 6 & ND \\
\hline 14.747 & hexadecenenitrile & 5.5 & ND \\
\hline 15.845 & docosane & 13 & ND \\
\hline 16.652 & tricosane & 20 & ND \\
\hline 17.463 & hexanedioic acid, mono(2-ethylhexyl)ester & 25 & ND \\
\hline 18.256 & pentacosane & 8 & ND \\
\hline 19.023 & hexacosane & 8 & ND \\
\hline 18.568 & bis(2-ethylhexyl)phthalate & 5.5 & ND \\
\hline \multirow[t]{3}{*}{20.572} & squalen & 20 & ND \\
\hline & Total (kcounts) & 1585.5 & 187.25 \\
\hline & Residual (\%) & \multicolumn{2}{|c|}{11.81} \\
\hline
\end{tabular}

\subsection{Evaluation of Recycled CAF as Plant Growing Substrate}

Lavender seeds showed similar germination in both substrates, whereas the Spanish broom seeds showed a better germination in recycled CAF than those in SW substrate, with a steady difference at the end of the experiment (Figure 1A). Concerning stem cutting propagation, sage and rosemary generally showed similar capacity to form new roots in both substrates (Figure 1B). Accordingly, previous studies showed that the aforementioned species can successfully adapt to and grow on polluted soils near to or in (ex-) mining areas [22-24] and on dredged saline sediments [25], thus acting as effective decontaminating agents. Moreover, it was reported that Spanish broom germination is induced by the presence of pollutants [26,27], indicating that the remaining toxic compounds in recycled CAF may somehow activate physiological mechanisms improving germination and seedling establishment in this species. 
(A)

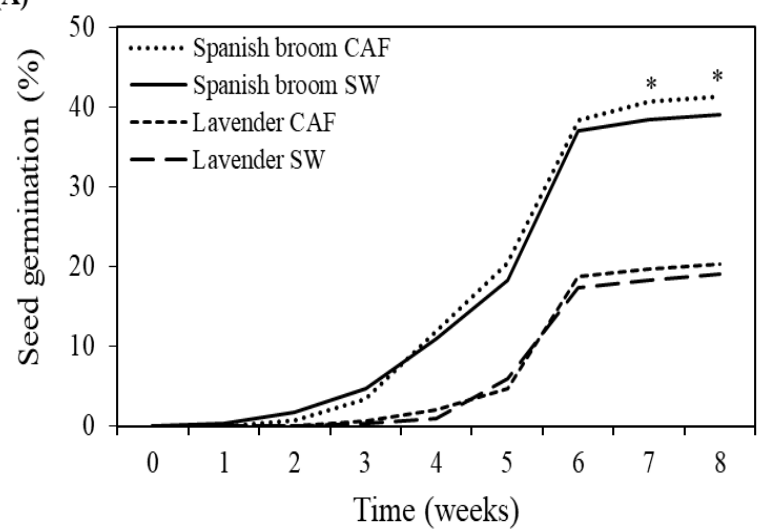

(B)

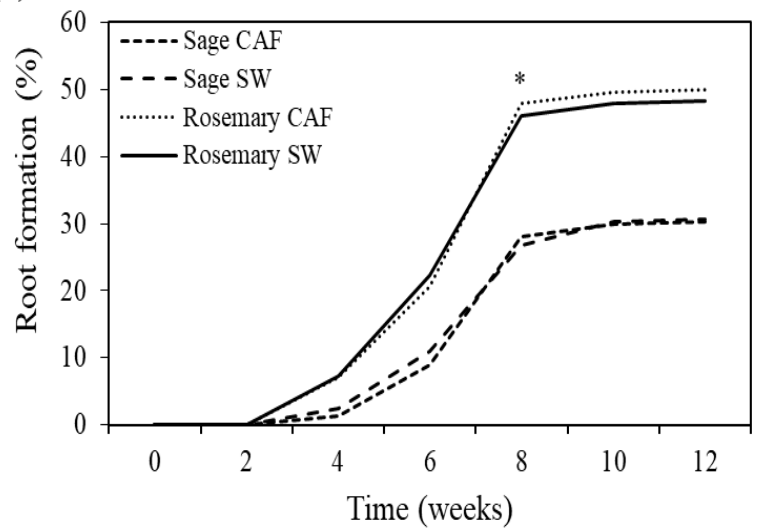

Figure 1. Effect of different substrates on the growth capacity in ornamental plants. (A) Seed germination (\%) of Spanish broom and lavender sowed in recycled cellulose acetate filters (CAF) or stone wool (SW) substrates. (B) Root formation (\%) of rosemary or sage stem cuttings propagated in CAF or SW substrates. Data are means of 3 replicates of 100 seeds or cuttings. Asterisks represent significant differences $(p<0.05)$ between substrates.

Spanish broom showed significantly higher concentrations of all photosynthetic pigments when sown in SW than in CAF, whereas only the carotenoids to total chlorophyll ratio (Car/Chla $+b)$ was unaffected by the different substrates (Table 2). Chla in lavender leaves was the only photosynthetic pigment significantly affected by substrates, where its concentration was significantly higher in SW than in CAF (Table 2). Concerning plant propagation by stem cutting, only sage showed significant differences in the concentration of Chla and Car as well as in Chla/Chlb, with higher values in plants grown in SW than in CAF (Table 2). Among pigments in rosemary, only Car was affected by substrates, showing higher concentration in plants grown in SW (Table 2). The effect of substrate on pigment content was clearly species-dependent, and this could be related to the capacity of each plant species to cope with remaining toxic compounds in CAF (Table 1). Accordingly, it has been demonstrated that nicotine [pyridine, 3-(1-methyl-2-pyrrolidinyl)] has differential effects on plants depending on species, e.g., chlorophyll content is decreased by nicotine in mung bean, whereas in maize it increased, due to its impact on nutrient uptake [28]. Moreover, different nicotine concentrations induce different response mechanisms in the same species affecting its growth and photosynthesis $[29,30]$. Benzonitrile, another remaining toxic compound in CAF, is a principal chemical group in common herbicides [31], acting as photosynthetic inhibitors with differential effects depending on species [32]. Similarly, the uptake and translocation capacity of dibutyl phthalate from root to shoot is genotypespecific, and can trigger the production and accumulation of reactive oxygen species (ROS), impairing the synthesis of photosynthetic pigments [33-37]. Besides the aforementioned pollutants, silicon ( $\mathrm{Si}$ )-based compounds, including silanes, were the most abundant in CAF (Table 1). Interestingly, it has been reported that Si can induce or reinforce the regulation of secondary metabolites in plants, mitigating numerous environmental constraints [38]. Thus, it could be possible that in the CAF substrate, Si contributes to the alleviation of the exogenous pollutants stress by activating physical or molecular mechanisms [38]. 
Table 2. Effect of different substrates on photosynthetic pigments in ornamental plants. Chlorophyll $a(\mathrm{Chl} a)$, chlorophyll $b(\mathrm{Chl} b)$ and carotenoids (Car) concentration expressed in $\mu \mathrm{g} / \mathrm{mg}$ fresh weight, ratios of Chl $a / \mathrm{Chl} b$ and Car/Chla $+b$ were determined in leaves of 8 week-old plantlets of Spanish broom and lavender or 12 week-old cuttings of sage and rosemary grown in recycled cellulose acetate filters (CAF) or stone wool (SW) substrates. Data are means of 3 different replicates. Asterisks represent significant differences $(p<0.05)$ between substrates.

\begin{tabular}{ccccccc}
\hline Species & Substrate & Chl $\boldsymbol{a}$ & Chl $\boldsymbol{b}$ & Car & Chla/Chl $\boldsymbol{c}$ & Car/Chl $\boldsymbol{a}+\boldsymbol{b}$ \\
\hline Spanish & CAF & 0.139 & 0.159 & 0.099 & 0.87 & 0.33 \\
broom & SW & $0.242^{*}$ & $0.205^{*}$ & $0.147^{*}$ & $1.17^{*}$ & 0.32 \\
\hline \multirow{2}{*}{ Lavender } & CAF & 0.611 & 0.327 & 0.344 & 1.86 & 0.36 \\
& SW & $0.665^{*}$ & 0.384 & 0.370 & 1.73 & 0.35 \\
\hline \multirow{2}{*}{ Sage } & CAF & 0.888 & 0.362 & 0.422 & 2.45 & 0.33 \\
& SW & $1.113^{*}$ & 0.360 & $0.497^{*}$ & $3.09^{*}$ & 0.33 \\
\hline \multirow{2}{*}{ Rosemary } & CAF & 0.856 & 0.288 & 0.368 & 2.97 & 0.32 \\
& SW & 0.863 & 0.330 & $0.396^{*}$ & 2.61 & 0.33 \\
\hline
\end{tabular}

Results of the maximum $\left(F_{v} / F_{m}\right)$ and actual $\left(\Phi_{\mathrm{PSII}}\right)$ photochemical efficiency of the PSII in the studied species did not show significant differences between substrates (Table 3), indicating that the generally low content of pigments did not affect the photosynthetic performances in plants grown in CAF. This means that the recycled CAF substrate was decontaminated enough and the remaining trace compounds did not generate an adverse effect on the photosynthetic system. However, the plant adaptation process may require a higher carbon allocation toward secondary rather than primary metabolism, e.g., synthesis of photosynthetic pigments [39]. Moreover, in the CAF substrate, a microbial activity contributing to limit the uptake of exogenous pollutants by plants is not to be excluded.

Table 3. Effect of different substrates on the chlorophyll $a$ fluorescence in ornamental plants. Maximum photochemical efficiency $\left(F_{v} / F_{m}\right)$ and photochemical yield in the light $\left(\Phi_{\text {PSII }}\right)$ of photosystem II (PSII) were assessed in leaves of 8 week-old plantlets of Spanish broom and lavender or 12 week- old cuttings of sage and rosemary grown in recycled cellulose acetate filters (CAF) or stone wool (SW) substrates. Data are means of 3 different replicates.

\begin{tabular}{cccc}
\hline Species & Substrate & $\boldsymbol{F}_{\boldsymbol{v}} / \boldsymbol{F}_{\boldsymbol{m}}$ & $\boldsymbol{\Phi}_{\text {PSII }}$ \\
\hline \multirow{2}{*}{ Spanish broom } & CAF & 0.836 & 0.730 \\
& SW & 0.827 & 0.721 \\
\hline \multirow{2}{*}{ Lavender } & CAF & 0.812 & 0.672 \\
& SW & 0.813 & 0.653 \\
\hline \multirow{2}{*}{ Sage } & CAF & 0.820 & 0.744 \\
& SW & 0.821 & 0.754 \\
\hline \multirow{2}{*}{ Rosemary } & CAF & 0.826 & 0.714 \\
& SW & 0.823 & 0.724 \\
\hline
\end{tabular}

\section{Conclusions}

It can be stated that filters from smoked CB have been successfully decontaminated by boiling water without the need for special solvents, and then recycled as soilless substrate for growing ornamental plants such as Spanish broom, lavender, sage and rosemary.

Our study demonstrated that the remaining trace compounds in recycled CAF substrate do not negatively affect the establishment of roots and progressive growth of the studied ornamental plants.

Altogether, turning filters from $\mathrm{CB}$ waste into a soilless substrate for growing ornamental plants is a novel solution to recycle $\mathrm{CAF}$, using an easy cleaning method suitable to be scaled up at an industrial level. Moreover, besides the production of CAF substrates, the recycling of all other components in the process can be possible, such as paper recy- 
cling (solid byproduct), reuse of water from CB wastewater treatment by microalgal-based remediation techniques, and the production of biofuel from microalgae.

A further advantage, such as zero cost unlimited CAF due to the massive waste of $\mathrm{CB}$, is the indirect reduction of waste flows deriving from the production of commercial SW substrate for the greenhouse industry.

Author Contributions: Conceptualization, L.G.; methodology, L.G. and L.M.; formal analysis, L.M., T.H.R., M.C. and L.G.; data curation, L.G. and T.H.R.; writing-original draft preparation, T.H.R.; writing-review and editing, L.G., T.H.R., L.M. and M.C.; supervision, L.G.; funding acquisition, L.G. All authors have read and agreed to the published version of the manuscript.

Funding: This research was funded by the Fondazione Cassa di Risparmio di Lucca-progetto FOCUS 2019/2021.

Institutional Review Board Statement: Not applicable.

Informed Consent Statement: Not applicable.

Data Availability Statement: Data is contained within the article.

Acknowledgments: We thank Otello Malfatti (Department of Agriculture, Food and Environment, University of Pisa) for his assistance during the handmade preparation of substrate plugs and plant management. The authors also thank the Municipality of Capannori for the disposal management of cigarette butts.

Conflicts of Interest: The authors declare no conflict of interest. The funders had no role in the design of the study; in the collection, analyses, or interpretation of data; in the writing of the manuscript, or in the decision to publish the results.

\section{References}

1. Acuña, R.A.; Bonachela, S.; Magán, J.J.; Marfà, O.; Hernández, J.H.; Cáceres, R. Reuse of rockwool slabs and perlite grow-bags in a low-cost greenhouse: Substrates' physical properties and crop production. Sci. Hortic. 2013, 160, 139-147. [CrossRef]

2. López-Pérez, J.A.; Edwards, S.; Ploeg, A. Control of root-knot nematodes on tomato in stone wool substrate with biological nematicides. J. Nematol. 2011, 43, 110-117. [PubMed]

3. Bar-Tal, A.; Saha, U.K.; Raviv, M.; Tuller, M. Inorganic and synthetic organic components of soilless culture and potting mixtures. In Soilless Culture; Elsevier: Amsterdam, The Netherlands, 2019; pp. 259-301. ISBN 9780444636966.

4. de la Hera, G.; Muñoz-Díaz, I.; Cifrian, E.; Vitorica, R.; Gutierrez San Martin, O.; Viguri, J.R. Comparative Environmental Life Cycle Analysis of Stone Wool Production Using Traditional and Alternative Materials. Waste Biomass Valorization 2017, 8, 1505-1520. [CrossRef]

5. Yap, Z.S.; Khalid, N.H.A.; Haron, Z.; Mohamed, A.; Tahir, M.M.; Hasyim, S.; Saggaff, A. Waste Mineral Wool and Its Opportunities-A Review. Materials 2021, 14, 5777. [CrossRef] [PubMed]

6. Dannehl, D.; Suhl, J.; Ulrichs, C.; Schmidt, U. Evaluation of substitutes for rock wool as growing substrate for hydroponic tomato production. J. Appl. Bot. Food Qual. 2015, 88, 68-77. [CrossRef]

7. Kurmus, H.; Mohajerani, A. The toxicity and valorization options of cigarette butts. Waste Manag. 2020, 104, 104-118. [CrossRef]

8. Hoffmann, D.; Hoffmann, I. The changing cigarette, 1950-1995. J. Toxicol. Environ. Health 1997, 50, 307-364. [CrossRef]

9. World Health Organization. Tobacco and Its Environmental Impact: An Overview; World Health Organization: Geneva, Switzerland, 2017; ISBN 9789241512497.

10. Oliva, M.; De Marchi, L.; Cuccaro, A.; Pretti, C. Bioassay-based ecotoxicological investigation on marine and freshwater impact of cigarette butt littering. Environ. Pollut. 2021, 288, 117787. [CrossRef]

11. Selmar, D.; Radwan, A.; Abdalla, N.; Taha, H.; Wittke, C.; El-Henawy, A.; Alshaal, T.; Amer, M.; Kleinwächter, M.; Nowak, M.; et al. Uptake of nicotine from discarded cigarette-A so far unconsidered path of contamination of plant-derived commodities. Environ. Pollut. 2018, 238, 972-976. [CrossRef]

12. Booth, D.J.; Gribben, P.; Parkinson, K. Impact of cigarette butt leachate on tidepool snails. Mar. Pollut. Bull. 2015, 95, 362-364. [CrossRef]

13. Rebischung, F.; Chabot, L.; Biaudet, H.; Pandard, P. Cigarette butts: A small but hazardous waste, according to European regulation. Waste Manag. 2018, 82, 9-14. [CrossRef] [PubMed]

14. Marinello, S.; Lolli, F.; Gamberini, R.; Rimini, B. A second life for cigarette butts? A review of recycling solutions. J. Hazard. Mater. 2020, 384, 121245. [CrossRef]

15. Yousefi, M.; Kermani, M.; Farzadkia, M.; Godini, K.; Torkashvand, J. Challenges on the recycling of cigarette butts. Environ. Sci. Pollut. Res. 2021, 28, 30452-30458. [CrossRef] [PubMed] 
16. Korobushkin, D.I.; Garibian, P.G.; Pelgunova, L.A.; Zaitsev, A.S. The earthworm species Eisenia fetida accelerates the decomposition rate of cigarette butts on the soil surface. Soil Biol. Biochem. 2020, 151, 108022. [CrossRef]

17. Rocha, C.S.; Rocha, D.C.; Kochi, L.Y.; Carneiro, D.N.M.; dos Reis, M.V.; Gomes, M.P. Phytoremediation by ornamental plants: A beautiful and ecological alternative. Environ. Sci. Pollut. Res. 2022, 29, 3336-3354. [CrossRef] [PubMed]

18. Huarancca Reyes, T.; Scartazza, A.; Bretzel, F.; Di Baccio, D.; Guglielminetti, L.; Pini, R.; Calfapietra, C. Urban conditions affect soil characteristics and physiological performance of three evergreen woody species. Plant Physiol. Biochem. 2022, 171, 169-181. [CrossRef]

19. Mariotti, L.; Huarancca Reyes, T.; Ramos-Diaz, J.M.; Jouppila, K.; Guglielminetti, L. Hormonal Regulation in Different Varieties of Chenopodium quinoa Willd. Exposed to Short Acute UV-B Irradiation. Plants 2021, 10, 858. [CrossRef]

20. Huarancca Reyes, T.; Pompeiano, A.; Ranieri, A.; Volterrani, M.; Guglielminetti, L.; Scartazza, A. Photosynthetic performance of five cool-season turfgrasses under UV-B exposure. Plant Physiol. Biochem. 2020, 151, 181-187. [CrossRef]

21. Poppendieck, D.G.; Khurshid, S.S.; Emmerich, S.J. Measuring Airborne Emissions from Cigarette Butts: Literature Review and Experimental Plan; National Institute of Standards and Technology: Gaithersburg, MD, USA, 2016.

22. Raveau, R.; Fontaine, J.; Bert, V.; Perlein, A.; Tisserant, B.; Ferrant, P.; Lounès-Hadj Sahraoui, A. In situ cultivation of aromatic plant species for the phytomanagement of an aged-trace element polluted soil: Plant biomass improvement options and techno-economic assessment of the essential oil production channel. Sci. Total Environ. 2021, 789, 147944. [CrossRef]

23. Affholder, M.-C.; Laffont-Schwob, I.; Coulomb, B.; Rabier, J.; Borla, A.; Boudenne, J.-L.; Demelas, C.; Prudent, P. Implication of phytometabolites on metal tolerance of the pseudo-metallophyte-Rosmarinus officinalis- in a Mediterranean brownfield Chemosphere 2020, 249, 126159. [CrossRef]

24. Pistelli, L.; D'Angiolillo, F.; Morelli, E.; Basso, B.; Rosellini, I.; Posarelli, M.; Barbafieri, M. Response of spontaneous plants from an ex-mining site of Elba Island (Tuscany, Italy) to metal(loid) contamination. Environ. Sci. Pollut. Res. 2017, 24, 7809-7820. [CrossRef] [PubMed]

25. Masciandaro, G.; Di Biase, A.; Macci, C.; Peruzzi, E.; Iannelli, R.; Doni, S. Phytoremediation of dredged marine sediment: Monitoring of chemical and biochemical processes contributing to sediment reclamation. J. Environ. Manag. 2014, 134, 166-174. [CrossRef] [PubMed]

26. Caniani, D.; Masi, S.; Mancini, I.M.; Trulli, E. Innovative reuse of drinking water sludge in geo-environmental applications. Waste Manag. 2013, 33, 1461-1468. [CrossRef] [PubMed]

27. Masi, S.; Caniani, D.; Grieco, E.; Lioi, D.S.; Mancini, I.M. Assessment of the possible reuse of MSW coming from landfill mining of old open dumpsites. Waste Manag. 2014, 34, 702-710. [CrossRef]

28. Farooq, M.; Hussain, T.; Wakeel, A.; Cheema, Z.A. Differential response of maize and mungbean to tobacco allelopathy. Exp. Agric. 2014, 50, 611-624. [CrossRef]

29. Cheng, Y.-D.; Bai, Y.-X.; Jia, M.; Chen, Y.; Wang, D.; Wu, T.; Wang, G.; Yang, H.-W. Potential risks of nicotine on the germination, growth, and nutritional properties of broad bean. Ecotoxicol. Environ. Saf. 2021, 209, 111797. [CrossRef]

30. Alkhatib, R.; Alkhatib, B.; Abdo, N. Impact of exogenous nicotine on the morphological, physio-biochemical, and anatomical characteristics in Capsicum annuum. Int. J. Phytoremediation 2021, 1-9. [CrossRef]

31. Tadeo, J.; Sánchez-Brunete, C.; Pérez, R.; Fernández, M. Analysis of herbicide residues in cereals, fruits and vegetables. J. Chromatogr. A 2000, 882, 175-191. [CrossRef]

32. Sanders, G.E.; Pallett, K.E. Studies into the differential activity of the hydroxybenzonitrile herbicides. Pestic. Biochem. Physiol. 1986, 26, 116-127. [CrossRef]

33. Li, Y.; Yan, H.; Yu, X. Uptake and accumulation of di-n-butyl phthalate in six leafy vegetables under hydroponic conditions. Food Prod. Process. Nutr. 2019, 1, 9. [CrossRef]

34. Virgin, H.I.; Holst, A.-M.; Morner, J. Effect of di-n-butylphthalate on the carotenoid synthesis in green plants. Physiol. Plant. 1981, 53, 158-163. [CrossRef]

35. Kumari, A.; Kaur, R. A review on morpho-physiological traits of plants under phthalates stress and insights into their uptake and translocation. Plant. Growth Regul. 2020, 91, 327-347. [CrossRef]

36. Zhao, H.-M.; Huang, H.-B.; Du, H.; Xiang, L.; Mo, C.-H.; Li, Y.-W.; Cai, Q.-Y.; Li, H.; Liu, J.-S.; Zhou, D.-M.; et al. Global Picture of Protein Regulation in Response to Dibutyl Phthalate (DBP) Stress of Two Brassica parachinensis Cultivars Differing in DBP Accumulation. J. Agric. Food Chem. 2018, 66, 4768-4779. [CrossRef] [PubMed]

37. Dong, Y.; Song, Z.; Liu, Y.; Gao, M. Polystyrene particles combined with di-butyl phthalate cause significant decrease in photosynthesis and red lettuce quality. Environ. Pollut. 2021, 278, 116871. [CrossRef]

38. Luyckx, M.; Hausman, J.-F.; Lutts, S.; Guerriero, G. Silicon and Plants: Current Knowledge and Technological Perspectives. Front. Plant Sci. 2017, 8, 1-8. [CrossRef]

39. Herms, D.A.; Mattson, W.J. The Dilemma of Plants: To Grow or Defend. Q. Rev. Biol. 1992, 67, 283-335. [CrossRef] 